\title{
MOTIVACIONES DE LA EMIGRACIÓN VENEZOLANA RECIENTE HACIA ARGENTINA. EL CASO DE SANTA ROSA-TOAY, LA PAMPA, ARGENTINA
}

\section{MOTIVATIONS OF VENEZUELAN RECENT IMMIGRATION TO ARGENTINA. THE CASE OF SANTA ROSA-TOAY, LA PAMPA, ARGENTINA}

\section{María Dolores Linares*}

\section{RESUMEN}

El objetivo de este artículo es analizar las motivaciones de movilización de las personas migrantes provenientes de Venezuela al momento de iniciar sus trayectorias migratorias hacia Argentina entre los años 2010-2019, con el fin de determinar si se trata de una migración forzada o voluntaria. Para esto, se realizó la revisión de bibliografía especializada, estadísticas nacionales y provinciales, así como, la realización de entrevistas a profundidad a un total de 15 personas migrantes venezolanas en el aglomerado Santa Rosa-Toay (La Pampa). Conceptualmente, se discuten las categorías de exilio, refugio y diáspora para proponer, a manera de hipótesis, que la noción de migración por carencia permite incorporar tanto la voluntariedad como la no voluntariedad para caracterizar la ola migratoria venezolana en el área de estudio.

\section{PALABRAS CLAVE: EMIGRACIÓN * VENEZUELA * MOTIVACIÓN * ARGENTINA * REFUGIADO *} MIGRACIÓN LABORAL

\section{ABSTRACT}

This article's objective is to analyze the motivations of recent migrants from Venezuela to begin their migration trajectories towards Argentina between 2019 and 2019. Through the review of specialized literature, national and local statistics and in-depth interviews conducted with 15 Venezuelan migrants in Santa Rosa-Toay (La Pampa), we are interested in determine whether it is a forced or voluntary migration. Conceptually, the categories of exile, refuge (right of asylum) and diaspora will be discussed to propose, as a hypothesis,

Instituto de Estudios Históricos y Sociales de La Pampa, Universidad Nacional de La Pampa y Consejo Nacional de Investigaciones Científicas y Técnicas (CONICET), Argentina.

linares.dolores@gmail.com 
that the notion of migration due to privation (Cozzani de Palmada, 2005) allows the incorporation of both voluntary and non-voluntary characteristics to describe the Venezuelan migration in our study area.

KEYWORDS: EMIGRATION * VENEZUELA * MOTIVATION $*$ ARGENTINA * REFUGEE * LABOUR MIGRATION

\section{INTRODUCCIÓN}

Este trabajo trata sobre las motivaciones de la migración venezolana reciente en la República Argentina desde una perspectiva que recupera la experiencia de las personas migrantes. La emigración de personas venezolanas ha sido masiva en estos últimos diez años (desde el año 2010), el Departamento de Asuntos Económicos y Sociales de Naciones Unidas (ONU DAES) estima que 437280 venezolanos se encontraban fuera de su país en el año 2005, cifra que ascendería a más de cuatro millones para el 2019 (Alto Comisionado de Naciones Unidas para los Refugiados [ACNUR], 2019).

Según estadísticas de la Dirección Nacional de Migraciones (DNM), en el periodo de 2015 a 2018, los pedidos de residencia de parte de personas venezolanas en Argentina aumentaron a un ritmo vertiginoso, incrementando de 12000 en el año 2015 a 130000 en el año 2018 (Dirección Nacional de Migraciones, República Argentina, 2019).

Como problema de investigación, la migración venezolana reciente en Argentina se enmarca en un contexto complejo que, como establecen Koechlin et al. (2018), involucra un cambio del patrón migratorio sin precedentes, tanto en su cantidad, en su composición $y$ en su dirección. En este sentido, los autores describen cuatro oleadas migratorias desde el año 2002: la primera tuvo lugar luego de la asunción del presidente Hugo Chávez Frías, estuvo compuesta por profesionales de clase alta e investigadores ${ }^{1}$ (Freitez, 2011; Panadés,

1 Sobre la cualificación de la emigración venezolana como problema de investigación para el período 1960-2016, con referencia a la emigración de intelectuales, consultar a Requena y Caputo (2016). De la Vega (2005), analiza el período 1980-1990, y De la Vega y Vargas (2014), lo amplían hasta
2011; Mateo y Ledezma; 2006; Requena y Caputo, 2016) que partieron mayoritariamente hacia los Estados Unidos de América, España y Francia. La segunda ola migratoria se originó a partir del año 2007 y estuvo conformada por personas ciudadanas pertenecientes a las clases medias $y$ altas, profesionales $y$ empresarios que decidieron abandonar el país y mudar sus empresas, lo cual generó una notoria fuga de capitales. La asunción del presidente Nicolás Maduro en el año 2013, inició la tercera ola, compuesta por personas ciudadanas de clase media, en su mayoría con estudios universitarios y terciarios, que deciden partir de su país en busca de mejores condiciones para desarrollar sus profesiones. Según sus posibilidades, eligieron los destinos tradicionales y los países sudamericanos. Finalmente, la cuarta ola, se observa desde el año 2016 y estaría conformada por personas ciudadanas de clase media $y$ baja quienes buscaban trabajo o ingresos para sobrevivir (Koechlin et al., 2018). En este caso, la emigración está dirigida hacia los países cercanos, especialmente Colombia (según datos de la Oficina del ACNUR (2019), emigraron 48714 personas venezolanas en 2015 y 676093 en el 2019), Brasil (5000 en 2015 y 74860 en 2019), así como al resto de los países de Sudamérica.

Los autores determinan la periodización de las diferentes olas migratorias por los factores de expulsión, relativas a las medidas de los presidentes Hugo Chávez Frías y Nicolás

2014. Allen y Fazito (2017) analizan los stocks de migrantes calificados venezolanos en el período 2001-2011. Para profundizar sobre el análisis de la "fuga de cerebros" o migración cualificada, ver también Freitez (2011), Panadés (2011), Mateo y Ledezma (2006), y Baldwin (2017). Un completo análisis de la migración selectiva se encuentra en el trabajo de Sala (2019), para el caso de los ingenieros venezolanos en Argentina. 
Maduro. Para la primera ola, los factores de expulsión fueron el despido masivo de 20000 trabajadores de PDVSA y la confección de "listas negras" de opositores (como la lista de Tascón o de Maisanta), mientras que las medidas que causaron la segunda ola serían el referéndum por la reelección indefinida, las expropiaciones de tierras y empresas, y por la estatalización de canales de televisión contrarios al régimen. La administración de Maduro da comienzo a la tercera ola a partir del control de precios, la devaluación del bolívar y la promulgación de la Ley de precios Justos, que fomentó el cierre de casi 78000 empresas en Venezuela (Castillo $y$ Reguant, 2017). Por último, la cuarta ola se explicaría por la inflación descontrolada (de acuerdo a Castillo y Reguant, 2017, los datos del FMI indican que en el año 2016 fue del 475,5\%), el desabastecimiento de alimentos, artículos de higiene $y$ medicamentos (que conlleva un auge del mercado negro) así como, la violencia organizada y generalizada (Freitez, 2011).

Estas olas sucesivas y su relación con la crisis política-económica-institucional de Venezuela, plantean otro inconveniente para el abordaje de este objeto de estudio teniendo en cuenta las motivaciones de la población migrante, es decir, si se trata de una migración forzada o voluntaria (Mármora, 2004). El libro compilado por José Koechlin y Joaquín Eguren (2018), "El éxodo venezolano: entre el exilio y la emigración", ilustra este problema, en la Introducción los autores aclaran que, teniendo en cuenta los motivos de la emigración, se puede hablar tanto de exilio (migración forzada) como de migración voluntaria.

Uno de los trabajos compilados, desde la perspectiva del modelo push and pull ${ }^{2}$, entiende a la personas migrante venezolana como

$2 \quad$ Este modelo responde a las teorías clásicas de las migraciones iniciadas con las Leyes de Ravenstein (1885, como se citó en Sassone, 1996), y se basa en la explicación de los movimientos de personas por los factores de atracción y de expulsión desde un abordaje principalmente económico. De esta manera, los desplazamientos se producen como consecuencia de la existencia de un diferencial económico entre dos zonas, siendo la dirección, siempre, desde las menos hacia las más desarrolladas y del campo a la ciudad. parte de una migración económica en Uruguay (Facal y Casal, 2018). Por otro lado, Farah (2018) analiza la migración venezolana en República Dominicana como un ejemplo de un sistema migratorio ${ }^{3}$, mientras que Edson Louidor (2018), la caracteriza como una migración forzada basándose en el Informe de la Comisión Interamericana de Derechos Humanos (CIDH) del año 2018 (CIDH, 2018), al utilizar las categorías de exilio y ayuda humanitaria para analizar la "diáspora" venezolana ${ }^{4}$. La coexistencia de dos categorías migratorias (migrante económico y migrante forzado) también se evidencia en el ámbito institucional internacional, ya que el Alto Comisionado de Naciones Unidas para los refugiados se refiere indistintamente a "refugiados y migrantes venezolanos" (ACNUR, 2019). Por último, mientras se realizaba el trabajo de campo con personas migrantes venezolanas en Santa Rosa-Toay (La Pampa), se evidenciaron tempranamente características propias de este colectivo que los distinguían de otras personas

$3 \quad$ Este modelo da cuenta de la existencia de ciclos o sistemas de migración que se estructuran a lo largo del tiempo y del espacio. Estos sistemas se caracterizan por el intenso intercambio de bienes, capital y población entre algunos países y menos intenso entre otros. En los sistemas hay una región de recepción central y un conjunto de países de origen ligados a estos por un flujo inusualmente largo (Fawcet, 1989; Zlotnik, 1992, como se citó en Massey et al., 1993). Aunque la teoría de los sistemas migratorios no es propiamente una teoría, se sostiene a partir de una serie de hipótesis explicativas. Un sistema migratorio se puede establecer entre países geográficamente lejanos, aunque los flujos son más abundantes entre países cercanos; pueden existir sistemas multipolares cuando hay países ricos dispersos que reciben migrantes de sus países vecinos, los países pueden pertenecer a más de un sistema migratorio. La estabilidad de los sistemas no significa una estructura fija dado que estos pueden cambiar a medida que las condiciones económicas y políticas se modifican.

4 La utilización de ambos términos: "migración económica" y "migración forzada", también se observa en los capítulos de otra obra colectiva coordinada por Luciana Gandini, Fernando Lozano Ascencio y Victoria Prieto (2019), "Crisis y migración de población venezolana. Entre la desprotección y la seguridad jurídica en Latinoamérica”. 
migrantes internacionales (Linares, 2016). En los relatos de las personas migrantes venezolanas entrevistadas surgían los términos "salir" y "huir"5 de Venezuela, lo que lleva a cuestionar la voluntariedad o no del inicio de sus trayectorias migratorias.

Por estas razones, el objetivo de este artículo es indicar las motivaciones de las personas migrantes provenientes de Venezuela entre los años 2010 y 2018 al momento de iniciar sus trayectorias migratorias hacia la Argentina, $y$ analizarlas a fin de comprender si se trata de migraciones forzadas o voluntarias a partir de un estudio de caso con los migrantes venezolanos en Santa Rosa-Toay ${ }^{6}$ (Provincia de La Pampa). Como se indicará en el apartado metodológico, para la realización de este propósito se utilizó un abordaje mixto cuantitativo y cualitativo, a partir de relevo de bibliografía especializada, estadísticas nacionales y provinciales, así como, la realización de entrevistas en profundidad a un total de 15 personas migrantes venezolanas en el aglomerado Santa Rosa-Toay. Se considera que este trabajo puede contribuir al esclarecimiento de categorías apropiadas para la comprensión de la migración venezolana de la última década en numerosos países latinoamericanos.

Para ordenar esta argumentación, se inicia describiendo los lineamientos teóricos conceptuales que guían el abordaje, mientras

5 Estos términos se tratan de "categorías nativas", en tanto le otorgan sentido y contextualizaban las relaciones de las personas entrevistadas con la realidad que protagonizan, permitiendo un acercamiento a su particular visión del mundo. Como expresa Roxana Guber (2005), el investigador mediante la "tarea de deslindar categorías propias y categorías nativas, en el aprendizaje del empleo de conceptos locales y la formulación de interrogantes significativos" (p. 45), puede recoger información con la cual reconstruir el complejo descriptivoexplicativo del mundo social en estudio.

Se ha tomado por el momento como unidad de análisis el aglomerado urbano que incluye las ciudades de Santa Rosa (Departamento Capital) y Toay (Departamento Toay), aunque pertenece a una jurisdicción departamental diferente, Toay es la ciudad satélite más importante del Gran Santa Rosa dado su cercanía geográfica y su relevancia demográfica. que el segundo apartado estará dedicado a las técnicas y estrategias metodológicas. Luego, se indicarán las características de la migración venezolana en la Argentina y en La Pampa. En cuarto lugar, se examinarán, a partir de la sistematización de las fuentes primarias, las variables resultantes de este trabajo exploratorio relacionadas con la distinción entre migraciones voluntarias y forzadas. En las conclusiones se retomarán los resultados del trabajo y las líneas para futuros análisis.

\section{REVISIÓN TEÓRICA Y CONCEPTUAL PARA EL ANÁLISIS DE LA MIGRACIÓN VENEZOLANA RECIENTE}

Sin pretender efectuar un relevo exhaustivo de las teorías que intentan explicar las migraciones internacionales, es necesario asumir un punto de partida desde el cual abordar la migración venezolana entre los años 2010 y 2019. Siguiendo a Massey et al. (1993), Arango (2003) y Aruj (2015), se encuentra una literatura tradicional e interdisciplinaria que ha intentado explicar las causas de la migración. Estos trabajos fueron muy prolíferos a partir del modelo neoclásico económico y microecónomico, el primero centrándose fundamentalmente en los factores estructurales de los mercados de trabajo (redistribución espacial de los factores de producción) y el segundo en la persona migrante como actor racional que toma la decisión de migrar a partir de un elaborado análisis de costos-beneficios.

Surgieron otras teorías de corte económico, que Aruj (2015) denomina de alcance medio por tener en cuenta factores explicativos globales (macro, según el autor) y microsociales, como las de push and pull, la nueva economía de la migración, $y$ la del mercado de trabajo dual. Massey et al. (1993), también destaca que algunas de estas teorías dan cuenta de factores estructurales que terminan perpetuando los flujos migratorios, tales como, la teoría de acumulación causal, la institucional, la de redes migratorias o la de los sistemas migratorios?.

\footnotetext{
7 La idea central de este conjunto de teorías o abordajes, es que los inicios de los flujos internacionales migratorios (motivados por diversas causas) en
} 
Esta investigación adopta un enfoque micro-analítico que no considera a las decisiones individuales de las personas migrantes como escindidas de las condiciones y condicionantes externos, sino como participantes de una realidad social mucho más compleja. Enfocar a las sujetas y los sujetos no significa, como establece Revel (2015), oponer un "arriba" sobre un "abajo" ni un "grande" sobre un "pequeño", sino reconocer -y utilizar como herramienta heurística- que "una realidad social no es la misma según el nivel de análisis o [...] la escala de observación en la que decidamos ubicarnos" (Revel, 2015, p.15). Por esta razón, la perspectiva de las redes sociales migratorias ${ }^{8}$ fue útil

ocasiones no explican su perpetuidad en el tiempo, una vez que las causas que la originaron cambian. Por esa razón, se enfocan en las nuevas condiciones surgidas en el proceso de la migración que se independizan de la causa original: redes, instituciones $y$ las significaciones del cambio social en las sociedades receptoras $y$ de destino. Dentro de esta línea, el proceso conocido como de "acumulación causal" tiene en cuenta seis factores: la distribución de los ingresos, la distribución de la tierra, la organización de la agricultura, la cultura de la migración, la distribución regional del capital humano y la significación social del trabajo. A partir de los cambios sociales, económicos y culturales producto de los flujos iniciales, tanto en origen como en destino, estas migraciones se retroalimentan y conceden resistencia a las posibles políticas de control de los gobiernos (Stark, Taylor y Yitzhari, 1986; Taylor, 1992, como se citó en Massey, et al., 1993). La teoría institucional, por su parte, se centra en las instituciones privadas o públicas que, luego de iniciados los primeros flujos, satisfacen la demanda de movilidad. Pueden tratarse de organizaciones que intentan facilitar la migración como una ONG de ayuda humanitaria, aunque también de aquellas dedicadas al mercado negro de la migración y la trata de personas.

Dentro de una perspectiva histórica- estructural, la teoría de las redes migratorias explica la perpetuación de los flujos migratorios a partir de las facilidades de los sujetos de lograr una trayectoria exitosa gracias a la existencia de una red. El flujo inicial habilita la red que luego se expande a diferentes miembros de la comunidad en el país de origen, hasta independizarse de las causas originales del primer flujo. Luego de un momento masivo, el flujo tiende a estabilizarse $y$ a decrecer. Las redes pueden desalentarse con políticas públicas restrictivas o fomentarse a partir de medidas como la reunificación familiar. para focalizar a las sujetas y los sujetos migrantes $y$ a sus grupos familiares como agentes productores y reproductores de lazos e información necesaria para la movilidad espacial. A la vez, se permite un planteamiento relacional que transita entre el plano micro de la adopción de decisiones individuales $y$ el plano macro de los determinantes estructurales de las migraciones (Faist, 1997, como se citó en Aruj, 2015). Las redes sociales son estructuras de carácter transnacional que involucran a todas aquellas personas e instituciones vinculadas al proceso migratorio: políticas públicas (en país de origen $y$ de destino), personas migrantes, empleadores, informantes, así como, asociaciones culturales, políticas, sociales y religiosas, entre otras (Pedone, 2010). Cuando se mencionan las trayectorias migratorias, se hace referencia a las trayectorias de vida que comprenden procesos espaciales integrados a la vida social y a la historia del sujeto.

Este enfoque resalta la subjetividad de la persona migrante que, además de reflejar sus expectativas, inquietudes, decisiones $y$ capacidades de agencia individuales $y$ familiares, también reconoce una época atravesada por normas $y$ valores compartidos por la sociedad de la que el sujeto forma - o desea formarparte. Respecto a estas subjetividades, interesa observar la auto-identificación -en términos de Brubaker (2001) — de la persona migrante en función de la voluntariedad o no de su trayectoria migratoria. Marta Inés Villa Martínez (2011), advierte sobre la dificultad observada al intentar analizar la adscripción o no a una de las categorías de migración forzada por parte de sus protagonistas. Eso se debe a que, más allá de las "condiciones objetivas", es la experiencia del sujeto y su relato lo que orientará la comprensión de los alcances, los efectos y las dimensiones de dichas condiciones en este caso.

Se trata entonces de definir los límites -imprecisos - entre la migración forzada y la voluntaria. Las migraciones se pueden definir como todo "desplazamiento residencial de población desde un ámbito socio-espacial a otro, entendiéndose por estos ámbitos el lugar donde las personas desarrollan la reproducción cotidiana de su existencia" (Mármora, 2004, 
p.89). Pueden ser voluntarias cuando los sujetos migrantes, motivados por mejorar sus condiciones de vida o por conocer otras condiciones, toman la decisión de desplazarse hacia un destino específico; un ejemplo claro de este tipo de migración es la económica (Castles, 2003). La migración forzada, por otro lado, implica tanto una coacción externa directa (traslados obligados) para el desplazamiento, así como, una decisión tomada - en un abanico de opciones reducidas - por temor a perder la vida o la libertad. En este último caso, la migración no responde a los beneficios esperados en el país de destino, sino al miedo de permanecer en el país de origen.

Las migraciones forzadas incluyen un conjunto de categorías legales o políticas con una característica común: que las sujetas y los sujetos migrantes se han visto obligados a abandonar su lugar de residencia para buscar refugio en otro lugar (Castles, 2003). María Virginia Casasfranco (2002), analiza el caso de Colombia y Centroamérica en el período 19702000 y propone, dentro de las migraciones forzadas, las categorías de migración por violencia como consecuencia de los procesos armados y la migración por eventos naturales, al tener en común la vivencia de hechos traumáticos - pérdidas humanas y materiales-y la producción de desplazados y solicitantes de refugio. Dentro de la migración por violencia, se podrían incluir las figuras de exilio y refugio (teniendo en cuenta la relación país de origen/ país de destino) fundadas en persecuciones políticas, religiosas, étnicas (García, 2017). El caso de la emigración venezolana reciente ha sido trabajado por Guardia Rolando (2007) y por Roniger (2010), a partir de la categoría de exilio y refugio, especialmente para las personas emigradas de la primera y segunda ola, mientras que la tercera y cuarta ola invita a discutir las migraciones económicas de supervivencia (Mármora, 2004) como otro tipo de migración forzada.

El término exilio se asocia al ámbito de lo político y de aquellas medidas -económicas, sociales, ambientales- que se toman en dicho ámbito. Según Roniger y Sznajder (2013), el exilio es un mecanismo de exclusión institucional que se puede realizar mediante la expulsión, la deportación u otras formas legales, y se usa para revocar el pleno uso de los derechos de ciudadanía. La figura del exiliado vincula entonces al individuo con su país de origen (Schwarzstein, 2001) y tiene la característica de implicar la conformación de comunidad en el país de destino, al unirse los exiliados no solo por su nacionalidad sino por su afiliación política, causa inicial del alejamiento de su país de origen. Las investigaciones sobre el exilio español (Schwarzstein, 2001) o los exilios latinoamericanos producto de las dictaduras cívico-militares de los años 60 y 70 (García, 2017), dan cuenta de otra categoría que sirve para analizar el exilio: del deseo de retorno. El proyecto de retorno a su país, una vez que las condiciones políticas lo permitan, es según Roniger (2010), una constante en los estudios sobre el exilio

Si bien, el exilio tiene una connotación política que vincula al ciudadano con su país de origen, la figura del refugio vincula al sujeto con el país de destino. El refugio es una figura jurídica que se extendió a partir de la creación del Alto Comisionado de Naciones Unidas para los Refugiados (ACNUR) en el año 1949 y que en Argentina es garantizado por la Comisión Nacional para Refugiados (CONARE), creada en el año 2006 mediante la Ley nro. 26.165. La figura del refugio excede el ámbito de lo meramente político para poder solicitar refugio, la CONARE establece que se debe tener "fundados temores de ser perseguido" por motivos de raza, religión, nacionalidad, pertenencia a determinado grupo social $\mathrm{u}$ opiniones política. Aquí se conjugan tres elementos que darán sustento a su elegibilidad como refugiado: la persecución, el temor y la fundamentación, lo que acarrea no pocas discusiones en torno al carácter subjetivo del refugio, sobre todo basándose en el segundo elemento (Mármora, 2004). La CONARE también otorga el status de refugiado a la persona cuya "vida, seguridad o libertad se encuentran amenazadas por la violencia generalizada, los conflictos armados, las violaciones masivas de derechos humanos $u$ otras circunstancias que hayan perturbado gravemente el orden público" (Ley 26.165, 01 de diciembre de 2006). 
Estas categorías de migración forzada abonan, como explica Mezzadra (2005), una representación del migrante como un sujeto débil, victimizado, despojado de la opción de subjetivación. En ese sentido, el autor propone centrarse en la subjetividad migrante para explorar la "riqueza" de la que son portadores y su capacidad de agencia. Tomar como eje la experiencia del sujeto migrante "no equivale a borrar las causas «objetivas» del origen de la migración, tampoco significa olvidar el modo en que su condición está profundamente caracterizada por circunstancias de privación material y simbólica" (Mezzadra, 2005, p.46). La tensión entre la libertad de circulación del migrante y los condicionantes externos permite proponer la categoría de derecho de fuga, que evita el reduccionismo sobre los migrantes en general ${ }^{9} y$ busca comprender las estrategias individuales de cada sujeto para huir de las causas objetivas que lo condicionan. En este caso de estudio, se dará cuenta de esta tensión, a partir de la reflexión realizada por los migrantes sobre su propia experiencia.

\section{ABORDAJE METODOLÓGICO}

La estrategia metodológica se centró, por un lado, en el relevamiento de bibliografía especializada en la emigración venezolana y el análisis de fuentes estadísticas argentinas (CONARE, radicaciones DNM) e internacionales (ACNUR, ONU). Por otro lado, se realizaron entrevistas en profundidad a personas migrantes venezolanas en Santa Rosa-Toay para conformar una muestra del universo estudiado.

El aglomerado urbano seleccionado como área de estudio está compuesto por la ciudad de Santa Rosa, la capital provincial, de 103241 habitantes según el Censo 2010, y su ciudad satélite, Toay, con 12134 habitantes y se encuentra a $8 \mathrm{~km}$ de la capital. Aunque la Provincia de La Pampa no se caracteriza por ser un polo

9 Según Mezzadra (2005), este reduccionismo se presenta desde la academia y organizaciones sociales en dos sentidos: por su masividad, con términos como "aluvión" migratorio -en este artículo se retoma el término "ola" $-y$ desde su dimensión cultural, utilizando términos como "típico exponente de una cultura" o una etnia. migratorio atractivo, desde el último censo del año 2010, se ha observado una progresiva recepción de migrantes internacionales (Linares, 2016), entre los cuales se destacan los venezolanos por su crecimiento exponencial, similar al registrado a nivel nacional.

Para lograr esta muestra se utilizó la técnica de la bola de nieve y se realizaron 15 entrevistas presenciales a personas migrantes venezolanas ${ }^{10}$, entre diciembre de 2017 y junio de 2019 en las ciudades de Santa Rosa y Toay. Siguiendo las normas éticas de protección de la identidad y anonimato, se refiere a los entrevistados como E1, E2 y así sucesivamente. Las entrevistas en profundidad se basaron en un cuestionario de 3 preguntas abiertas que respondían a 3 módulos destinados a brindar información que permitiera comprender y sistematizar los diferentes aspectos de la migración hacia La Pampa: 1) Módulo residencial, 2) Módulo de las redes sociales y 3) Módulo de la trayectoria laboral. Dentro de cada una de las preguntas abiertas se distinguieron $y$ analizaron 6 variables, sumando 18 en total. En esta oportunidad, en virtud del objetivo de este artículo, se ha sistematizado la información resultante de 4 variables del primer módulo: 1) los motivos de la migración, 2) la sensación de vulnerabilidad/persecución, 3) la posibilidad de retorno y 4) la reunificación familiar.

\section{MIGRACIÓN VENEZOLANA EN ARGENTINA Y EN LA PAMPA: CARACTERÍSTICAS GENERALES}

Argentina recibió, en mayor medida, a migrantes venezolanos de la tercera y cuarta ola. Aunque aún son escasos los trabajos que dan cuenta de este colectivo en el país, coinciden en la alta incidencia de migrantes profesionales (aproximadamente en un $77 \%$ ), una inserción laboral en sectores informales o precarizados (Pedone y Mallimaci, 2019) y la concentración en las grandes ciudades (Biderbast y Nuñez, 2018). La elección de Argentina como país de destino es explicada en razón de

10 Se toma cada caso como individual, aunque en 2 de los casos, los migrantes refirieron a otros miembros de la familia que aportaron datos o realizaron la entrevista, estos fueron contabilizados dentro del mismo caso/grupo familiar (E3, E3 madre, E4, E4 hijo, E5, E5 cónyuge, por ejemplo). 
las redes sociales establecidas en el país (Pedone y Mallimaci, 2019) y la posibilidad de radicación para permanecer de manera regular. La Ley de Migraciones 25.871 del año 2004, garantiza la migración como un derecho humano que el Estado debe resguardar y reconoce el derecho de acceso a la salud, la educación y la justicia a las personas migrantes, sin importar su condición documentaria. Por otra parte, los venezolanos en Argentina gozan de las facilidades de radicación gracias al Acuerdo de Residencia para los Nacionales de los Estados Partes y Asociados del MERCOSUR (2002) ${ }^{11}$. Además, durante el año 2018, se les extendieron los plazos para la presentación documentaria (Disposición DNM 594/2018) y se simplificaron los trámites para convalidar los títulos universitarios expedidos por instituciones venezolanas (Biderbast y Nuñez, 2018). Con respecto a la posibilidad de estos migrantes de apelar a la condición de refugiados, según las estadísticas de la CONARE, entre los años 2012 y 2015, solo 6 personas de origen venezolano habían solicitado refugio en Argentina, aumentando a 57 en el año 2016. En la página oficial del ACNUR (2019), se establece que han sido 1882 las solicitudes totales de refugio de venezolanos en Argentina hasta el año 2019.

Sobre la cantidad de migrantes venezolanos en Argentina, la información disponible se circunscribe hasta ahora a los pedidos de radicación en la DNM. En el año 2015, se resolvieron 4707 radicaciones de venezolanos según las estadísticas, pero los pedidos fueron aumentando significativamente desde esa fecha hasta llegar a más de 70000 en 2018, superando numéricamente a los pedidos de radicación de ciudadanos de países vecinos (gráfico 1). Una de las limitaciones de esta información es que no indica el año de llegada al país, dado que se trata de un trámite voluntario que el migrante puede realizar en cualquier momento.

\section{GRÁFICO 1 \\ RADICACIONES RESUELTAS TOTALES POR AÑO Y NACIONALIDAD \\ 2016-2018}

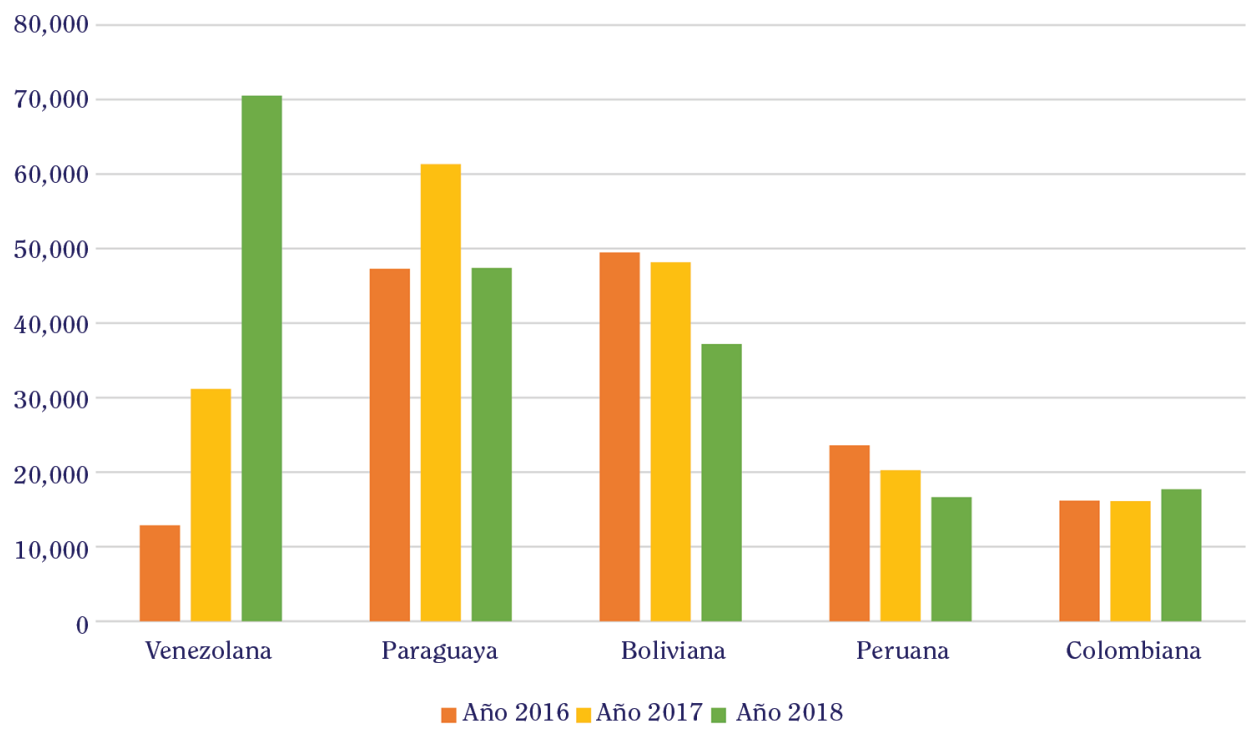

Fuente: $\quad$ Elaboración propia con base en las estadísticas de la Dirección Nacional de Migraciones, 2016-2018 (DNM, 2019).

11 Aprobado a nivel nacional mediante la Ley 25.902, publicada en el Boletín Oficial en julio de 2004. 
Según Biderbast y Nuñez (2018), los migrantes venezolanos buscan radicarse en: 1) grandes ciudades, 2) ciudades donde haya oportunidades laborales $y / 03$ ) existencia de redes de apoyo. El aglomerado urbano seleccionado para nuestro análisis es una ciudad intermedia. El último registro censal del año 2010 indicaba que La Pampa contaba con 3447 habitantes que habían nacido en el extranjero, cifra que representa el 1,08\% de su población total y la ubica muy por debajo de la media nacional, que asciende al 4,5\%. Desde el año 2016, se advierte un aumento significativo de migrantes venezolanos según las radicaciones resueltas por la DNM, como figura en el gráfico 2.

\section{GRÁFICO 2 \\ LA PAMPA: RADICACIONES RESUELTAS \\ 2004-2018}

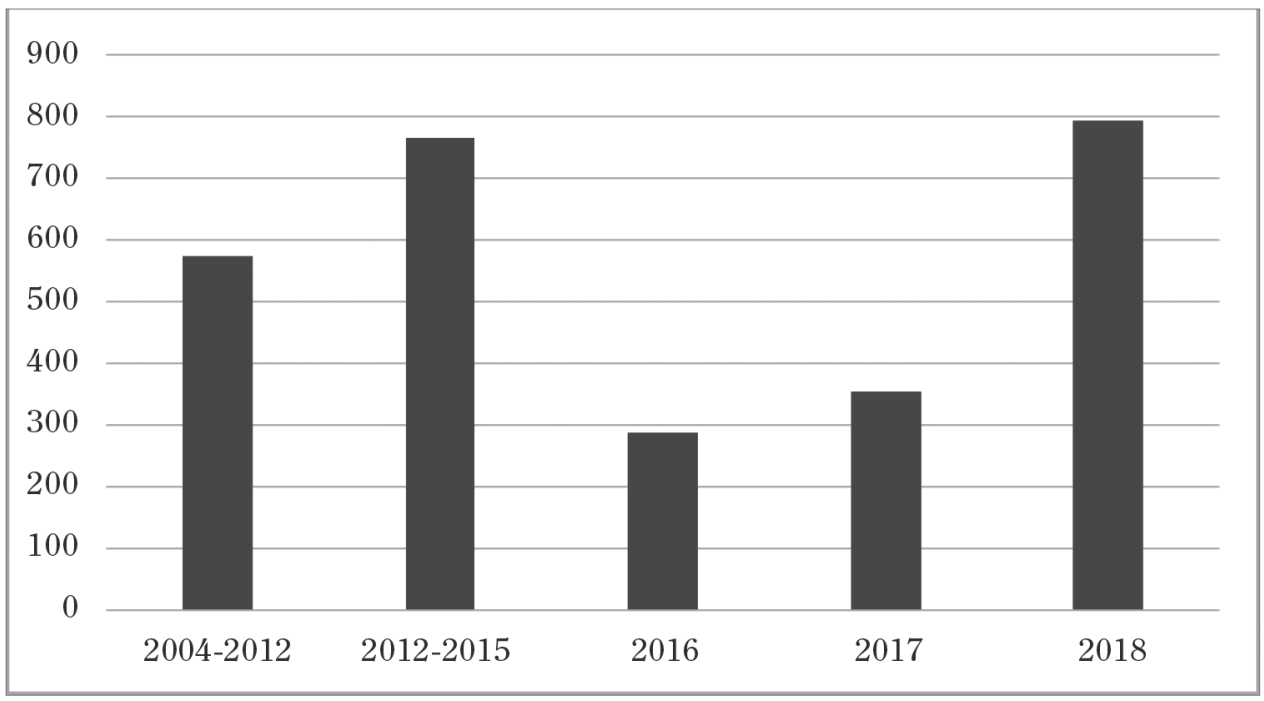

Fuente: $\quad$ Elaboración propia a partir de datos de las estadísticas de la DNM (2019) y de comunicación personal (DNM, 2013).

Sobre la cantidad de personas ciudadanas venezolanas que residen en la provincia, un alto funcionario de la DNL Delegación La Pampa ${ }^{12}$ confirmó que fueron 307 los trámites iniciados en el año 2018 y 122 hasta agosto de $2019^{13}$. En el año

12 Entrevistas a alto funcionario DNM, Delegación La Pampa. Realizadas en los años 2018 y 2019, Santa Rosa.

13 Hay que tener en cuenta que estos números no reflejan la realidad de aquellos que residen en la provincia por tres razones: 1) se trata de todos los trámites iniciados, tanto de residencia como de prórroga de residencia, con lo cual se puede realizar un doble conteo, 2) dado que en esta delegación los turnos
2018, los pedidos de residencia de venezolanos superaron por primera vez en La Pampa a las nacionalidades más tradicionales: paraguayos $y$ bolivianos. Entre las personas migrantes venezolanas entrevistadas, aproximadamente 150 residen en Santa Rosa-Toay (según sus redes de

son otorgados en un día, muchos migrantes de otras provincias, pero especialmente de la Ciudad Autónoma de Buenos Aires, viajan a La Pampa para realizar sus trámites documentarios de manera más rápida y luego regresan a sus lugares de residencia y 3) hay casos donde inician el trámite pero luego se mudan a otros lugares del país. 
contactos) y en su gran mayoría (todos excepto dos) arribaron a Argentina entre los años 2016 y 2018. Este aglomerado urbano ofrece tres características atractivas: una red de contactos, "mayor tranquilidad" en relación a las metrópolis y facilidades para obtener la residencia temporal o permanente. La mayoría de ellos cuenta con títulos universitarios o terciaros, pero su inserción laboral se caracteriza por la precariedad o el quiebre profesional (trabajos no acordes a su formación). Sobre las redes sociales, se han revelado fundamentales para el arribo a la Provincia de La Pampa y para la obtención de los primeros empleos. Los venezolanos en Santa Rosa-Toay no cuentan aún con agrupaciones institucionalizadas sino que se comunican por medio de un grupo virtual (whatssap) que oscila entre 40 y 60 miembros.
ENTRE LA MIGRACIÓN FORZADA Y VOLUNTARIA: MIGRACIÓN POR CARENCIA O PRIVACIÓN

Como se indicó anteriormente, las personas migrantes entrevistadas en Santa Rosa-Toay pertenecerían, en su mayoría, a la cuarta ola, por haber salido de Venezuela a partir del año 2016. Como se observa en el cuadro 1 , sobre el perfil de las personas entrevistadas, nueve eran mujeres $y$ seis hombres de entre 30 y 40 años. Seis de ellos vivían en Caracas al momento de decidir su trayectoria migratoria y otros residían en el Estado Anzoátegui, en Miranda, en Sucre, en Portuguesa y en Aragua. De los quince, trece habían realizado estudios terciarios (tecnicaturas) y seis tenían además un título universitario. La mayoría de ellos nunca había pensado ni deseado migrar como un proyecto de vida previo al inicio de su trayectoria migratoria. 
CUADRO 1

PERFILES DE LAS PERSONAS MIGRANTES ENTREVISTADAS

\begin{tabular}{|c|c|c|c|c|c|c|c|}
\hline NRO & EDAD & $\begin{array}{c}\text { GÉNERO } \\
\text { AUTO } \\
\text { PERCIBIDO }\end{array}$ & PROCEDENCIA & $\begin{array}{c}\text { AÑO } \\
\text { LLEGADA } \\
\text { A ARG. }\end{array}$ & $\begin{array}{l}\text { TRABAJA EN } \\
\text { ARGENTINA }\end{array}$ & $\begin{array}{l}\text { NIVEL DE } \\
\text { ESTUDIOS }\end{array}$ & $\begin{array}{c}\text { FECHA } \\
\text { ENTREVISTA }\end{array}$ \\
\hline E1 & 36 & M & Caracas & 2010 & $\begin{array}{c}\text { Sí } \\
\text { (negocio propio) }\end{array}$ & Universitario & Dic. 2017 \\
\hline E2 & 43 & $\mathrm{~F}$ & Caracas & 2012 & $\begin{array}{c}\text { Sí } \\
\text { (negocio propio) }\end{array}$ & Universitario & Mar. 2018 \\
\hline E3 & $30 / 40$ & $\mathrm{~F}$ & Caracas & 2017 & $\begin{array}{c}\text { Sí } \\
\text { (secretaria) }\end{array}$ & Universitario & Abril 2018 \\
\hline $\mathrm{E} 4$ & $30 / 40$ & $\mathrm{~F}$ & $\begin{array}{l}\text { Anaco (Estado } \\
\text { Anzoátegui) }\end{array}$ & 2017 & $\begin{array}{c}\text { Sí } \\
\text { (gastronomía) }\end{array}$ & $\begin{array}{l}\text { Secundario } \\
\text { Universitario } \\
\text { incompleto }\end{array}$ & Mayo 2018 \\
\hline E5 & $30 / 40$ & $\mathrm{~F}$ & $\begin{array}{l}\text { Anaco (Estado } \\
\text { Anzoátegui) }\end{array}$ & 2017 & $\begin{array}{c}\text { No } \\
\text { (busca) }\end{array}$ & Universitario & Junio 2018 \\
\hline E6 & $30 / 40$ & M & $\begin{array}{c}\text { Caracas/Los Teques } \\
\text { (Estado Miranda) }\end{array}$ & 2017 & $\begin{array}{c}\text { Sí } \\
\text { (gastronomía) }\end{array}$ & Universitario & Julio 2918 \\
\hline E7 & 41 & M & $\begin{array}{c}\text { Cumaná (Estado } \\
\text { Sucre) }\end{array}$ & 2016 & $\begin{array}{c}\text { Sí } \\
\text { (gastronomía) }\end{array}$ & Terciario & $\begin{array}{l}\text { Noviembre } \\
2018\end{array}$ \\
\hline E8 & 42 & M & $\begin{array}{c}\text { Acarigua (Estado } \\
\text { Portuguesa) }\end{array}$ & 2018 & $\begin{array}{c}\text { No } \\
\text { (solo changas) }\end{array}$ & Universitario & Diciembre 2018 \\
\hline E9 & $30-40$ & $\mathrm{~F}$ & $\begin{array}{c}\text { Maracay (Estado } \\
\text { Aragua) }\end{array}$ & 2018 & $\begin{array}{c}\text { No } \\
\text { (solo changas) }\end{array}$ & Universitario & Enero 2019 \\
\hline E10 & 36 & $\mathrm{~F}$ & $\begin{array}{c}\text { Anaco (Estado } \\
\text { Anzoátegui) }\end{array}$ & 2018 & $\begin{array}{l}\text { Sí } \\
\text { (cuidado de } \\
\text { personas) }\end{array}$ & $\begin{array}{l}\text { Terciario, } \\
\text { Universitario } \\
\text { incompleto }\end{array}$ & Enero 2019 \\
\hline E11 & $30-40$ & $\mathrm{~F}$ & $\begin{array}{l}\text { Anaco (Estado } \\
\text { Anzoátegui) }\end{array}$ & 2018 & $\begin{array}{c}\text { No } \\
\text { (busca) }\end{array}$ & Terciario & Enero 2019 \\
\hline E12 & 26 & $\mathrm{~F}$ & Caracas & 2018 & $\begin{array}{c}\text { Sí } \\
\text { (emprendimiento } \\
\text { propio) }\end{array}$ & Universitario & Febrero 2019 \\
\hline E13 & 31 & M & Caracas & 2018 & $\begin{array}{c}\text { Sí } \\
\text { (emprendimiento } \\
\text { propio) }\end{array}$ & Universitario & Febrero 2019 \\
\hline E14 & 38 & $\mathrm{~F}$ & $\begin{array}{c}\text { Anaco (Estado } \\
\text { Anzoátegui) }\end{array}$ & 2017 & $\begin{array}{l}\text { Sí. Empleada de } \\
\text { comercio }\end{array}$ & $\begin{array}{l}\text { Universitario } \\
\text { incompleto }\end{array}$ & Junio 2019 \\
\hline E15 & 37 & $\mathrm{~F}$ & $\begin{array}{l}\text { Anaco (Estado } \\
\text { Anzoátegui) }\end{array}$ & 2018 & $\begin{array}{l}\text { Sí. Empleada de } \\
\text { comercio }\end{array}$ & $\begin{array}{l}\text { Universitario } \\
\text { incompleto }\end{array}$ & Agosto 2019 \\
\hline
\end{tabular}

Fuente: $\quad$ Elaboración propia con base en las entrevistas realizadas en el conglomerado Santa Rosa-Toay en el período 2017-2019. 
Con respecto a la selección y presentación de las variables que se analizarán en este apartado, se debe aclarar que la "linealidad" temporal dentro del relato de una trayectoria de vida es una construcción difícil de amalgamar. La sistematización de la información resultante de las biografías relevadas demuestra que, aunque los relatos quieran ordenarse representando una carrera de "postas" que respete un tiempo diacrónico, la variedad de ámbitos que abarcan los hechos (laborales, familiares, espaciales, educativos, vida reproductiva) hace que varíen de dirección y de intensidad. Por esta razón, ante la pregunta abierta sobre la trayectoria migratoria, todos los entrevistados comenzaban explicando las causas de su "salida" o "huida" de Venezuela, pero estos motivos iniciales de la migración, sus percepciones sobre el régimen político y sobre la situación económica en Venezuela, fueron atravesando todo el relato.

Sobre la primera variable referida a los factores de expulsión, se observa una escasa incidencia de migraciones motivadas por "encontrar un lugar en el mundo" o "por amor" -en términos de Roca, Soronellas y Bodoque (2012) - motivos que habían caracterizado a las trayectorias de migrantes provenientes de otros países hacia La Pampa (Linares, 2016; 2017). Para el caso venezolano, solo dos de los entrevistados migraron a la Argentina por esos motivos y salieron de su país antes del año 2013, jactándose de ser, durante varios años, "los únicos dos venezolanos en La Pampa" (E1, comunicación personal, diciembre de 2017, Santa Rosa). El resto de los entrevistados (13 de los 15), "salieron" o "huyeron" de su país de origen luego del año 2015 para evitar una situación que atravesaban o temían atravesar, como la falta de alimentos, de medicinas y de productos de higiene, o a causa del temor por su seguridad personal frente a la delincuencia organizada, entre otros factores. Si bien, E7 arribó a La Pampa "por amor", como se observa a continuación, ya había emprendido su trayectoria migratoria hacia la Argentina en busca de mejores condiciones para ayudar a sus siete hijos que continúan en Venezuela:
A)

\section{FACTORES DE EXPULSIÓN}

(...) aunque tenía cuatro o cinco lugares donde daba clases no me alcanzaba para vivir: no se conseguía papel higiénico, toalla, pasta dental, los productos de higiene personal básicos ni el consumo básico de alimentos, como pollo, huevo... eso empezó a escasear mucho, eso me obligó a salir de Venezuela, lo que no se hizo fácil, bueno (Remarcado de la autora; E2, comunicación personal, marzo de 2018, Santa Rosa).

Sucede que cada día la cosa se estaba poniendo más difícil y así como yo hui, están huyendo cada día más venezolanos de Venezuela. Es una huida... nosotros no queremos "ir a probar nuevos caminos" (...) cuando ya dices: -ay! Estoy loca por irme, no aguanto el hambre, la escasez, la falta de medicinas, mi hijo no tiene pañales, ya mi hijo no tiene leche! Yo lloraba todas las noches, era una situación desesperante... (Remarcado de la autora; E4, comunicación personal, mayo de 2018, Santa Rosa).

(...) podría haberme quedado en Venezuela. (...) No sentí persecución política (...) Un amigo me dijo que puedo irme a Canadá o a EEUU y que como trabajé en el gobierno provincial con gobiernos de oposición puedo pedir asilo político. Pero ellos investigan y tienes que demostrarlo (...) Me parece la manera más vil y cínica de aprovecharse de algo que no es. Mucha gente lo hizo sin ser perseguido. Yo me fui perseguido por el hampa, por la inseguridad, eso sî (Remarcado de la autora; E6, comunicación personal, julio de 2018, Toay).

(...) yo me venía por amor, digamos así. Digamos no, esa es la palabra: me vine a La pampa por amor. Porque por ayudar a mis 
hijos, en cualquier parte del país los podría haber ayudado. Vine por conocer a esa chica de La Pampa que ahora es mi pareja (E7, comunicación personal, noviembre 2018, Santa Rosa).

Es una salida como forzada, porque es diferente cuando tu te vas porque quieres cambiar de vida o no sé qué, pero ya eso es una alternativa, uno u otro país. En nosotros no es eso (E11, comunicación personal, enero de 2019, Santa Rosa).

En las primeras entrevistas, las personas migrantes utilizaron el término "huir de Venezuela"; esta expresión fue retomada para indagar sobre sus sensaciones frente a estas condiciones objetivas de carencia de alimentos $y$ otros artículos de primera necesidad (medicamentos, pañales, etcétera). Esta búsqueda llevó a identificar en casi todos los casos una sensación de vulnerabilidad e injusticia, en ocasiones definida por una persecución política indirecta -nunca directa-y en otras por la percepción de un sistema socio-político y económico injusto, que no garantizaba seguridad frente al accionar violento de bandas delictivas o de la corrupción generalizada. Esta información se agrupa bajo la categoría de percepciones de vulnerabilidad/persecución.

\section{B) PERCEPCIONES DE VULNERABILIDAD/ PERSECUCIÓN}

Tengo una prima que no está trabajando y Maduro está ahora con bonos y bonos: de navidad, de reyes magos, de carnaval, dinero para todo el mundo, una cosa impensable. Y a mi prima le tocó todo. Y ella no está a favor de Maduro pero igual cuando vinieron las elecciones en diciembre votó por él porque si deja de votar (...) los tienen a todos controlados, le quitan la bolsa de comida y todos los bonos y todo el ingreso $y$ ella no tiene trabajo y no consigue trabajo (E3, comunicación personal, abril de 2018, Santa Rosa).
Cuando yo llegué el hospital como especialista, y la directora era en categoría menos que yo, eso a ella no le beneficiaba mucho y que yo siempre he sido opositor al gobierno, a este gobierno o al gobierno de Chávez (...) y entonces ella me quería mandar (...) ella era antichavista antes pero cuando le dieron el cargo de directora se volvió chavista, madurista...entonces tuve mucho destrato con ella (E8, comunicación personal, diciembre de 2018, Santa Rosa).

Yo no soy oposición, no. Y lo mantengo $y$ lo digo donde sea (...) Con los venezolanos me he reunido dos o tres veces, no te lo voy a negar, pero luego conoces algunos que disparan una cantidad de veneno y ya como que uno no quiere saber más nada, aunque seamos compatriotas. (...) hay mucho odio, mucho (E9, comunicación personal, enero de 2019, Santa Rosa).

(...) ya la calidad del estudio no es la misma (...) ahorita en los estudios a los chicos le quieren meter el comunismo $y$ el socialismo, le quieren lavar el cerebro (E10, comunicación personal, enero de 2019, Santa Rosa).

A mí se me ha reducido mucho allá lo que es la parte laboral, porque allá si tu estás en contra del sistema político, como que te marcan y ya, listo. Yo soy docente, maestra jardinera, $y$ hace un tiempo los cargos por concurso fueron eliminados del país, ahora es todo a dedo. Yo salí en un concurso, mi cargo era para un colegio público, pero simplemente porque yo firmé un referéndum en contra del presidente Chávez entonces me quitaron mi cargo y quedé marcada (E11, comunicación personal, enero de 2019, Santa Rosa). 
A mí una vez me apuntaron con un arma en la cabeza frente al edificio donde vivía mi tía. Imagínate que ella hubiese salido a abrirme y me hubiese visto ahí muerta. Son esas cosas que dices "qué estoy haciendo aquí"? Conozco gente de la calle donde yo vivía, en el pueblito, que las secuestraban dentro de sus casas, las amordazaban, y a la policía la teníamos en la esquina de la calle! Nadie hace nada, no tienes quién te defienda (E13, comunicación personal, febrero de 2019).

Estas dos primeras variables, íntimamente relacionadas, muestran diferentes dimensiones de carencia percibidas: económica, política, educativa, institucional. Las experiencias relatadas tienen un denominador común: un sistema socio-político-económico que perciben como el causante de las carencias sufridas. Estas vivencias individuales, sumadas, demuestran una situación experimentada colectivamente (extendido a familiares, amigos, vecinos). Fueron entonces estos dos elementos combinados, las carencias y el sistema estructural que las originaba, los determinantes al momento de tomar la decisión individual/familiar de migrar, porque los sujetos sentían que pese a sus esfuerzos no podían cambiar su situación dentro del país de origen. El recuerdo de estas carencias, recurrente en sus relatos, servía para justificar y aceptar las precariedades sufridas una vez arribados a Santa Rosa-Toay.

De hecho, el desplazamiento migratorio llevó a las personas entrevistadas a tolerar ciertas precariedades (laborales, residenciales, por ejemplo), porque eran percibidas como circunstancias que formaban parte de un momento transitorio para evitar sufrir más carencias, mientras aguardan regresar a su país. Diez de los entrevistados y las entrevistadas pensaban en la posibilidad de retorno, aunque establecen que para hacerlo, la situación económica en Venezuela debería "normalizarse", lo que no evalúan posible en el corto plazo. Se considera que esta recurrencia a referirse al deseo de retorno pondría elementos para determinar si se trata de una migración forzada o voluntaria.
C) RETORNO

Por ahora no pienso en el retorno. Y cada vez más convencida que no, que no podemos. Así cambie el gobierno, va a tardar mucho, años, no es algo que vaya a cambiar de la noche a la mañana, está todo destruido... (E3, abril de 2018, Santa Rosa).

Después, si después Venezuela se acomoda, volvemos para atrás, me entiendes? Me voy de regreso a mi país! (Esposo de E5, junio de 2018, Santa Rosa).

Que más quisiera yo que volver a mi país! (...) pero todavía no están bien las cosas (E10, enero de 2019, Santa Rosa).

Cuando me fui de Venezuela en el año 2015 pensaba que iba a volver en un año, pero luego no fue así (...) y ahora está muy difícil volver y además toda mi familia se fue de Venezuela, ya no están allí (E12, febrero de 2019, Santa Rosa).

Otro eje recurrente en los relatos relacionado a la motivación y las posibilidades de su trayectoria migratoria era la reunificación familiar. La precariedad de la "situación transitoria" en el país de destino y el recuerdo de las carencias vivenciadas en su país de origen se volvían dolorosos para aquellos que habían decidido salir de Venezuela sin sus hijos, asumiendo que en algún momento podrían volver a estar juntos. De los 15 entrevistados, 12 tenían hijos, de los cuales solo 5 habían podido migrar con ellos o ya se habían reunificado al momento de realizar la entrevista. Las otras personas entrevistadas, padres y madres, llevaban entre 6 meses y 2 años sin vivir con sus hijos. Para ellos, el conseguir cualquier tipo de trabajo, aunque no se ajuste a sus preferencias profesionales, era menester para poder lograr la reunificación de la familia. 
D) REUNIFICACIÓN FAMILIAR

(...) claro que si puedo tener dos trabajos, para ganar mejor, tener mejor calidad de vida y traer a los niños, estaría bueno! (E2, marzo de 2018, Santa Rosa).

Tengo seis hijos allá (...) las ganas de traerlos están, pero es difícil (...). Si yo me vuelvo a verlos, me va a dar tanta cosita que me voy a querer quedar. Las despedidas son fuertes (E7, noviembre de 2018, Santa Rosa).

Antes de venirme busqué imágenes de la ciudad, de la catedral... y me da una cosa en el estómago porque yo le dije a mi hijo que viera los lugares donde yo iba a estar, para que (llora), para que cuando los buscara en el google se recordara que su mamá estaba allá (llora). Lo sentaba en mis piernas y le decía: -mira mi ángel, esta es la catedral! (E9, enero de 2019, Santa Rosa).

Mis jefes quieren que yo me quede en su casa hasta que pueda reunir el dinero para los pasajes de mis hijos (...) incluso mi jefa me ofrece regalarme los pasajes! (...) ahora en Venezuela están dando, para reunir a familias que están así, por lo menos a las mamás con sus hijos, un pasaporte provisional, en la DNM me lo dijeron, para la reunificación familiar (E10, enero de 2019, Santa Rosa).

Estas cuatro variables identificadas dan cuenta de una situación de migración muy particular. Casi todas las personas entrevistadas coincidieron en que "salían" de Venezuela por las privaciones económicas, pero "huían" del desabastecimiento extremo, de la inseguridad $y$ de la violencia organizada ("hampa", "bandas armadas", "grupos comando"). La mayoría sintió, además, el peso de un sistema político que consideraban corrupto e injusto, que no garantizaba su seguridad.
Se estima pertinente descartar para este caso, las teorías explicativas de corte meramente económico: las personas migrantes venezolanas entrevistadas no realizaron, ni individual ni en el seno familiar o comunitario, una evaluación costo-beneficio pensando en las diferencias salariales entre su país de origen y distintos destinos, ni en la oferta y demanda laboral, ni en las condiciones macroeconómicas de distintos países. No se trataría, para este caso, de una "migración económica" puramente voluntaria sino motivada por una carencia sentida como excesiva, por lo tanto, involuntaria. Aun así, este tipo de migración forzada se presenta sin una percepción de persecución política directa ni personalizada, sino motivada por una sensación de vulnerabilidad generalizada.

Asimismo, estas personas no manifestaron temor por su integridad física infundada por persecución política. De los cuatro migrantes que cronológicamente podrían pertenecer a la segunda y tercera ola, dos de ellos (E 1 y E 3), habían migrado antes del 2013 por amor, con lo cual no fueron las condiciones ni políticas ni económicas las que motivaron el inicio de su trayectoria migratoria. Pero dos restantes (E 12 y E 13), si bien tenían proyecto de viaje "turístico" por Latinoamérica, tomaron la decisión de migrar por haber sido víctimas de violencia por robo en varias oportunidades. Con esto se indica que entre los entrevistados y las entrevistadas no se encontraron sujetos que se ajusten por sus perfiles, a las tres primeras olas migratorias descriptas por Koechlin, Vega y Solórzano (2018).

Ninguna de las personas en este trabajo se consideró a sí mismo como exiliado o exiliada, aunque determinen que su salida del país no fue totalmente voluntaria. Por esta razón, la figura del exilio no podría aplicarse a estos sujetos migrantes, aunque queda por analizar la capacidad y la necesidad de formar comunidad en los países de destino congregados a partir de su afinidad política, característica que se ha observado en otros países (Guardia, 2007), pero que excede los objetivos de este estudio. Hasta ahora, la información resultante del Módulo de Redes Migratorias no ha permitido identificar agrupaciones de 
migrantes venezolanos aglutinadas alrededor de un compromiso político en Santa Rosa-Toay.

La figura del refugiado, sin embargo, podría amparar a las personas migrantes venezolanas de la cuarta ola, incluidos algunos de los entrevistados y las entrevistadas, sobre todo si se tiene en cuenta el deseo de escapar de una "situación de violencia generalizada". Un tercio de los entrevistados había sido víctima de robos en Venezuela y consideraban que su vida corría peligro si se quedaban en su país. Según el Estudio Global de Homicidios del año 2019 de la Unated Nations Office on Drugs and Crime (UNODC, 2019), Venezuela presentó en el año 2017, la tasa de homicidios intencionados más alta de Sudamérica, con 57 casos sobre 100 000 habitantes $^{14}$.

Igualmente, al considerar que la figura del refugiado tiene que ver con el status otorgado por el país de destino, en el caso argentino, las solicitudes de personas provenientes de Venezuela han sido relativamente escasas. Es posible que esta baja cantidad de solicitudes se deba a la facilidad proporcionada por la legislación argentina a estos migrantes, que no necesitarían el status de refugiado para lograr la residencia regular en el país. En las estadísticas de la página web del ACNUR, se evidencia que las solicitudes de refugio son mayores en los cuatro países de mayor destino de venezolanos pero que tienen, además, políticas migratorias más restrictivas que la argentina: Perú (287 114 solicitudes), Brasil (103 697), Estados Unidos de América (85 796) y España (48 690) (Naciones Unidas, 2018).

A partir de la experiencia de los entrevistados y las entrevistadas, se estima apropiado detenerse en la categoría de migración forzada "económica por supervivencia" (Mármora, $2004)^{15}$. Una noción útil es la propuesta de María Rosa Cozzani de Palmada (2005), sobre migración por carencia. La autora reconoce dos tipos de migración, "por carencia o exclusión" destinada a poder satisfacer necesidades

14 Ver: https://www.unodc.org/unodc/en/data-andanalysis/global-study-on-homicide.html

15 Para un análisis de tipos de "migración por supervivencia”, ver Betts (2013). elementales como empleo, ingresos suficientes para la subsistencia, libertad política, étnica, religiosa, seguridad jurídica, seguridad pública; y la "migración por insatisfacción", motivada por una percepción de falta relativa de realización de expectativas de progreso o de condiciones de calidad de vida superiores (Cozzani de Palmada, 2005). Este primer tipo de migración, por carencia, podría explicar la situación de la mayoría de los migrantes venezolanos en Santa Rosa-Toay. Se propone sustituirla por "migración por privación", ya que si bien, "carencia" es sinónimo de privación según el Diccionario de la Real Academia Española (RAE), la privación suma un elemento fundamental: el causante de la misma. El primer significado del diccionario para la noción de privación es "acción de despojar, impedir o privar" (página web RAE), con lo cual se responsabiliza de esta manera a un tercero por la carencia del sujeto. Dicho de otro modo, para la lengua española, en la privación es evidente que hay un actor que priva a otro de algo, acto que no está presente en el vocablo "carencia".

Los resultados del trabajo de campo indican que se trataría de una sensación de privación colectiva, ya que el desabastecimiento extremo de alimentos, medicinas y productos de higiene abarca a un gran porcentaje de la población y no se circunscribe a un grupo social determinado. Además, la privación no es solo de bienes sino también de servicios: los venezolanos advierten que los servicios públicos como el transporte, el correo y la administración pública no funcionan, generando largas esperas para ir al trabajo, conseguir un pasaporte o la apostilla de los títulos universitarios. Por último, la situación de violencia generalizada provoca una determinada privación de libertad. Las personas migrantes entrevistadas comparan con entusiasmo la libertad que sienten en Santa Rosa-Toay para salir a caminar en cualquier horario del día sin sentir temor por su seguridad física. Por estas razones, se considera que la privación es colectiva y general, porque se sufre en diferentes ámbitos de la vida social, e impulsa/fuerza a los venezolanos $y$ a las venezolanas a emprender la trayectoria migratoria. En última instancia, a ejercer su 
derecho de fuga (Mezzadra, 2005), su "huir" de Venezuela para escapar de esas condiciones "objetivas".

\section{PARA SEGUIR REFLEXIONANDO}

En este artículo se propuso analizar las motivaciones de las personas migrantes venezolanas al momento de iniciar sus trayectorias migratorias hacia Argentina, tomando como caso de estudio el aglomerado urbano de Santa Rosa-Toay en la Provincia de La Pampa. Interesaba determinar si eran migraciones voluntarias (motivadas por razones puramente económicas, por ejemplo) o forzadas (motivadas por la sensación de persecución política o por violencia). Especialmente, la inquietud se debía a que el cambio de patrón migratorio venezolano de las últimas décadas generó una dificultad para el análisis, evidenciado en la utilización de distintas categorías para describir, aparentemente, un mismo fenómeno que contaba, en realidad, con distintos perfiles migratorios. Por esta razón, además de diferenciar las sucesivas olas migratorias e indicar a cual pertenecían los migrantes en Argentina, es fundamental orientarse a partir de la capacidad de subjetivación del propio migrante sobre su condición. En el apartado teórico se explicó el modelo de las redes sociales migratorias adoptado para estudiar la migración venezolana a La Pampa y se realizó una breve revisión de las categorías clásicas que diferencian la migración forzada de la voluntaria.

Luego de describir la situación de los migrantes venezolanos recientes en Argentina y en Santa Rosa-Toay, se procedió a una exposición de la información recabada mediante la realización de 15 entrevistas en profundidad a migrantes venezolanos en Santa Rosa-Toay, a partir de cuatro variables: 1) factores de expulsión; 2) percepción de vulnerabilidad/persecución; 3) deseo de retorno y 4) reunificación familiar. El primer resultado de este trabajo de campo fue identificar que 11 de los 15 entrevistados habían salido de Venezuela a partir del año 2016, es decir, pertenecerían a la cuarta ola. De los cuatro que lo hicieron antes de esa fecha, dos migraron por amor $y$ otros dos por proyectos de viaje que terminaron por prolongarse en una trayectoria migratoria. Ninguno de los cuatro tiene el perfil de las tres primeras olas migratorias (clase alta o media alta, empresarios y profesionales, "exiliados"). Salvo estos últimos dos entrevistados, ninguno de los venezolanos en La Pampa había pensado en migrar antes de decidir emprender su trayectoria migratoria: 13 de los 15 opinaban que cambiar de país no era un proyecto de vida, no deseaban buscar nuevas experiencias ni su "lugar en el mundo". Los 11 entrevistados que salieron de Venezuela luego del 2016, lo hicieron porque sintieron que sufrían algún tipo de carencia.

En ese sentido, los motivos de su migración se explicaban a partir de las privaciones sufridas en Venezuela: de alimentos, de elementos de higiene, de medicamentos y de servicios básicos. Para otros, el motivo de su migración fue la búsqueda de seguridad por haber sufrido en su país de hechos delictivos. Ninguno de los entrevistados o las entrevistadas afirmó haber sentido persecución política directa personalizada. Pese a parecer, en primera medida, una migración por carencias "económicas", estos relatos se enlazaban seguidamente con las percepciones sobre un sistema político, económico e institucional injusto o corrupto, que era en última instancia el responsable de las privaciones. Corrupción a pequeña escala, imposibilidad de ascender laboralmente por posicionamientos políticos, sistema educativo sesgado, delincuencia organizada $y$ abandono institucional fueron las situaciones que llevaron a estos migrantes a pensar en salir de su país para poder acceder a derechos humanos básicos.

A partir de esta variable, la de vulnerabilidad/persecución, se estima que hay un componente importante de no voluntariedad en su trayectoria migratoria. En otras palabras, si la crisis no se hubiese agudizado, ellos no hubiesen migrado. Además, esta no-voluntariedad puede ser explicada a través de la variable de retorno, que demuestra la persistencia del deseo de regresar a su país de origen cuando estén dadas las condiciones necesarias para estos migrantes. Por último, la categoría de la reunificación familiar ilustra la gran incidencia de migrantes venezolanos que se separan de sus 
hijos para migrar y que esperan lograr estabilidad en el país de destino para que sus hijos dejen de vivenciar las mismas carencias.

Transitando entre la voluntariedad y la no voluntariedad, se intentó caracterizar esta ola migratoria hacia Argentina, en el caso de Santa Rosa-Toay, como una migración por privación, retomando la categoría de migración por carencia de Cozzani de Palmada (2005). Teniendo en cuenta que se trata de un flujo reciente y que continúa, se descarta por el momento el concepto de exilio hasta tanto se pueda observar el comportamiento de esta comunidad en este $y$ otros países. La figura de refugio podría explicar la situación de algunos de estos migrantes pero, por su escasa incidencia en Argentina, no se considera que sea generalizable. La noción de migración por carencia y exclusión, por otro lado, puede ser útil y generalizable si se tiene en cuenta sus características. Como explica Cozzani de Palmada (2005), esta movilidad está destinada a satisfacer necesidades básicas como el empleo, ingresos suficientes para la subsistencia, libertad política, étnica, religiosa, seguridad jurídica y seguridad pública. Además de agregarle el término privación, que implica la acción de un tercero que priva al sujeto, se ha sumado otras características que ayudan a dimensionar la privación de este colectivo migrante: es extrema, porque el desabastecimiento en alimentos, productos de higiene $y$ medicinas atenta contra la buena salud de la población. Es también general, porque además de bienes se ven privados de servicios básicos que afectan su vida cotidiana. Es colectiva, porque no afecta a familias ni a individuos aislados o a grupos sociales determinados, sino al conjunto de la sociedad.

Se considera que la propuesta de esta noción para caracterizar la cuarta ola migratoria venezolana en Argentina, a partir del caso de estudio Santa Rosa-Toay, puede ser revisada y reformulada a medida que se avance en el análisis de los diferentes aspectos que se ponen en juego en la trayectoria migratoria de los venezolanos $y$ las venezolanas en Argentina $y$ en otros países latinoamericanos. La distancia en el tiempo permitirá revisar las periodizaciones para describir las olas migratorias y las estadísticas utilizadas. Si se entiende a la migración como un hecho social total (Sayad, 2010), a medida que los estudios académicos avancen, se podrá comprender las condiciones en las que viven las personas migrantes venezolanas en Argentina, así como, las condiciones que los transformaron en emigrantes. Se deberán conjugar así una serie de aspectos que van más allá de las políticas públicas o económicas del país de destino, sino también del país receptor y de las experiencias de vida de los migrantes para poder definir apropiadamente las categorías migratorias que explicarán esta reciente, masiva y multidireccionada emigración sudamericana.

\section{REFERENCIAS}

Allen, A. J. y Fazito, D. (2017). Mecanismos de selectividad $y$ destinos principales de emigrantes argentinos $y$ venezolanos: un análisis comparado. Notas de Población (CEPAL), 105, 191-220.

Alto Comisionado de Naciones Unidas para los Refugiados [ACNUR]. (2019). Situación de Venezuela. https://www.acnur.org/situacion-en-venezuela.html

Arango, J. (2003). La explicación teórica de las migraciones: Luz y Sombra. Migración y Desarrollo. Red Internacional de Migración y Desarrollo, Zacatecas, Latinoamericanistas.

Aruj, R.S. (2015). Migraciones, disciplinamiento y control social: del sujeto colectivo a la masificación. Universidad Nacional de Tres de Febrero.

Baldwin, L. (2017). The Venezuelan Diaspora: A Cerebral Exodus. Latin American Studies: Student Scholarship \& Creative Works. Student Paper. https://digitalcommons. augustana.edu/ltamstudent/1

Betts, A. (2013). Survival Migration: Failed Governance and the Crisis of Displacement. Cornell University Press. https://www.jstor.org/stable/10.7591/j.ctt$32 \mathrm{~b} 5 \mathrm{~cd}$

Biderbast, P. y Nuñez, M. E. (2018). Del Río de la Plata al Orinoco y viceversa. Patrones $y$ flujos migratorios entre Argentina $y$ Venezuela. En J. Koechlin y J. Eguren Rodríguez (Eds.), El éxodo venezolano: 
entre el exilio y la emigración, (135166). Observatorio Iberoamericano sobre Movilidad Humana, Migraciones y Desarrollo. https://www.uarm.edu.pe/ FondoEditorial/etica-desarrollo/el-exodovenezolano-entre-exilio-emigracion\#. XMBwcqSvGUk

Brubaker, R. (2001) Au-delà de l'«identité». Actes de la recherche en sciences sociales, 139(1), 66-85.

Casasfranco, M. V. (2002). Las migraciones y los desplazamientos forzados: Análisis comparativo e integral desde un enfoque de derechos humanos (Retos en Centroamérica y Colombia). Fundación Arias para la Paz y el Progreso Humano, Centro de las Naciones Unidas para el Desarrollo de los Asentamientos Humanos, Centro de Investigación para el Desarrollo (IDRC), Canadá.

Castillo, T. y Reguant, M. (2017). Percepciones sobre la migración venezolana: causas, España como destino, expectativas de retorno. Migraciones, 41, 133163. https://doi.org/10.14422/mig.i41. y2017.006

Castles, S. (2003). La política internacional de la migración forzada. Migración y Desarrollo, 1. http://rimd.reduaz.mx/ revista/rev1/StephenCastles.pdf

Comisión Interamericana de Derechos Humanos [CIDH] (2018). Informe Anual de la Comisión Interamericana de Derechos Humanos de la Organización de Estados Americanos (OEA). http://www.oas.org/es/ cidh/docs/anual/2018/indice.asp

Cozzani de Palmada, M. R. (2005). Migración $y$ redes sociales transnacionales. Argentina, país de emigración. Bollettino Della Societa Geografica Italiana, XII, 463-473.

De La Vega, I. (2005). Mundos en movimiento. El caso de la movilidad y migración de los científicos y tecnólogos venezolanos. Editorial Fundación Polar.

De la Vega, I. y Vargas, C. (2014). Emigración intelectual y general en Venezuela: una mirada desde dos fuentes de información. Bitácora-e, 1, 66-92.
Dirección Nacional de Migraciones [DNM] (2019). Estadísticas Radicaciones en Argentina. https://www.argentina.gob.ar/interior/ migraciones/estadisticas

Dirección Nacional de Migraciones [DNM] (2013). Radicaciones La Pampa período 20042012. Comunicación personal, мемо $\mathrm{N}^{\circ}$ 10683/2013, Nota $N^{\circ} 2221 / 2013$.

Facal, S. y Casal, B. (2018). Un estudio sobre la inmigración actual de venezolanos en Uruguay. En Koechlin, J y Eguren Rodríguez, J. (Eds.), El éxodo venezolano: entre el exilio y la emigración, (186-250). Observatorio Iberoamericano sobre Movilidad Humana, Migraciones y Desarrollo.

Freitez, A. (2011). La emigración desde Venezuela durante la última década. Temas de Coyuntura, 63, 11-38.

Gandini, L., Lozano, F. y Prieto, V. (2019). Crisis y migración de población venezolana. Entre la desprotección y la seguridad jurídica en Latinoamérica. Universidad Nacional Autónoma de México.

García, M. B. (2017). Influencia de exiliados e instituciones en el proceso político que liga migraciones $y$ derechos humanos en Argentina (1983-2015). [Tesis para optar por el título de Doctor en Relaciones Internacionales, Universidad Nacional de Rosario]. Repositorio Hipermedial de la UNR.

Guardia, I. (2007). Fuga de venezolanos durante la Revolución Bolivariana (1998-2007). Investigaciones geográficas, (44), 187-198.

Guber, R. (2004). El salvaje metropolitano. Reconstrucción del conocimiento social en el trabajo de campo. Paidós.

Koechlin, J. y Eguren, J. (Eds.). (2018). El éxodo venezolano: entre el exilio y la emigración. Observatorio Iberoamericano sobre Movilidad Humana, Migraciones y Desarrollo. https://www.uarm.edu.pe/ FondoEditorial/etica-desarrollo/el-exodovenezolano-entre-exilio-emigracion\#. XMBwcqSvGUk

Koechlin, J., Vega, E. y Solórzano, X. (2018). Migración Venezolana al Perú: proyectos 
migratorios y respuesta del Estado. En Koechlin, J. y Eguren Rodríguez, J. (Eds.), El éxodo venezolano: entre el exilio y la emigración (pp.47-96). Observatorio Iberoamericano sobre Movilidad Humana, Migraciones y Desarrollo.

Ley 26.165. (01 de diciembre de 2006). Honorable Congreso de la Nación Argentina, Ley General de Reconocimiento y Protección al Refugiado. Boletín Oficial. http:// www.migraciones.gov.ar/pdf/conare/ Ley_26.165.pdf

Linares, M.D. (2016). Trayectorias migratorias e inserción laboral de migrantes recientes en Santa Rosa-Toay (La Pampa, Argentina). Pilquen Sección Ciencias Sociales, 19 (4), 32-46.

Linares, M. D. (2017). Tendencias recientes de las migraciones internacionales en $\mathrm{La}$ Pampa: políticas, instituciones y actores. En Andrea Lluch (Ed.), Desarrollo, politicas públicas e institucionales (pp. 222256). EdUNLPam.

Louidor, W. E. (2018). La migración forzada venezolana a Colombia (2015-2018): de una revisión documental a los esbozos de un análisis coyuntural y estructural. En J. Koechlin y J. Eguren, (Eds.), El éxodo venezolano: entre el exilio y la emigración, (pp. 21-46). Observatorio Iberoamericano sobre Movilidad Humana, Migraciones y Desarrollo.

Mármora, L. (2004). Las políticas de migraciones internacionales. Paidós.

Martínez, J. y Orrego, C. (2016). Nuevas tendencias y dinámicas migratorias en América Latina y el Caribe. Serie Población y Desarrollo. CEPAL-ONU-OIM. https://www. cepal.org/es/publicaciones/39994-nuevas-tendencias-dinamicas-migratorias-america-latina-caribe

Massey, D., Arango, J., Graeme, H., Kouaouci, A., Pellegrino, A. y Taylor, J. E. (1993). Theories of International Migration: A Review and Appraisal. Population and Development Review, 19 (3), 431-466.

Mateo, C. y Ledezma, T. (2006). Los venezolanos como emigrantes. Estudio exploratorio en
España. Revista Venezolana de Análisis de Coyuntura, 12(2), 245-267.

Mezzadra, S. (2005). Derecho de fuga. Migraciones, ciudadanía y globalización. Traficantes de Sueños.

Naciones Unidas. (2018), Venezuelan situation. https://data2.unhcr/org/en/situations/ vensit

Panadés, E. (2011). La emigración venezolana rumbo a España; características socio-demográficas e inserción laboral de una migración latinoamericana en tiempos de crisis. Temas de Coyuntura, (63), 39-68.

Paredes, F. (2018). La migración venezolana reciente en la República Dominicana a la luz de las teorías contemporáneas sobre las migraciones internacionales. En Koechlin, J y Eguren Rodríguez, J. (Eds.), El éxodo venezolano: entre el exilio y la emigración, (273-292). Observatorio Iberoamericano sobre Movilidad Humana, Migraciones y Desarrollo.

Pedone, C. (2010). Cadenas y redes migratorias: propuesta metodológica para el análisis diacrónico-temporal de los procesos migratorios. Empiria. Revista de Metodología de Ciencias Sociales, 19, 101-132.

Pedone, C. y Mallimaci, A. (2019). Trayectorias laborales de la población venezolana en la Ciudad Autónoma de Buenos Aires. En C. Blouin (Comp.), Después de la llegada. Realidades de la migración venezolana (pp. 129-148). Thēmis.

Requena, J. y Caputo, C. (2016). Pérdida de talento en Venezuela: migración de sus investigadores. Interciencia, 41(7), 444-453.

Revel, J. (2015). Juegos de escalas. Experiencias de microanálisis. Universidad Nacional de General San Martín, UNSAM EDITA.

Roca, J., Soronellas, M. y Bodoque, Y. (2012). Migraciones por amor: diversidad y complejidad de las migraciones de mujeres. Papers Revista de Sociología, 97 (3), 685707. http://papers.uab.cat/article/view/ v97-n3-roca-soronellas-bodoque

Roniger, L. (2010). Exilio político y democracia. América Latina Hoy, 55(0), 143-172. 
http://revistas.usal.es/index.php/11302887/article/view/7266

Roniger, L. y Sznajder, M. (2013). La política del destierro y el exilio en América Latina. Fondo de Cultura Económica.

Sala, A. G. (2019). Ingenieros venezolanos residentes en la República Argentina. Organización Internacional para las Migraciones. http://argentina.iom. int/co/sites/default/files/publicaciones/ INGENIEROS.pdf

Sassone, S. M. (1996). Migraciones internacionales. Protagonistas de nuestro tiempo. Geodemos, 4. PRIGEO-CONICET.

Sayad, A. (2010). La doble ausencia. De las ilusiones del emigrado a los padecimientos del inmigrado. Anthropos.

Schwarzstein, D. (2001). Migración, refugio y exilio: categorías, prácticas y representaciones. Estudios Migratorios Latinoamericanos, 16(48), 249-268
Unated Nations Office on Drugs and Crime [unodc]. (2019). Global Study on Homicide 2019, Booklet 2. https://www. unodc.org/documents/data-and-analysis/ gsh/Booklet2.pdf

Villa, M. I. (2011). Desplazados y refugiados: entre ser, merecer y ocultar su situación. A propósito de la migración forzada de colombianos en Colombia, Ecuador y Canadá. En B. Feldman-Bianco, L. Rivera Sánchez, C. Stefoni y M. I. Villa Martínez (Comps.), La construcción social del sujeto migrante en América Latina Prácticas, representaciones y categorías (pp. 339-366). FLACSO, CLACSO, Universidad Alberto Hurtado.

Fecha de ingreso: 13/09/2019 Fecha de aprobación: 10/06/2020 
